\title{
热带雨林冠层树种线毛番龙眼两种发育 阶段叶片的光抑制
}

\author{
蔡志全 曹坤芳 齐 欣 \\ (中国科学院西双版纳热带植物园, 云南预腊 666303)
}

\begin{abstract}
摘 要 通过测定西双版纳热带雨林冠层树种线毛番龙眼 (Pometia tomentosa) 完全伸展嫩叶和成熟叶的叶片解剖、 生理特征和雨季晴天自然条件下叶绿素 a 苂光以及午间强光对部分保护酶活性和膜脂过氧化作用的影响 探讨了 两种不同发育阶段叶片光合作用的光抑制与强光和温度的关系。结果表明 线毛番龙眼全展嫩叶和成熟叶表现出 明显的解剖和生理特征差异。与全展嫩叶相比,成熟叶的叶片较厚、叶绿素含量高、气孔导度大、羧化效率高、最大 净光合速率和光饱和点高, 而气孔密度和保卫细胞长度没有显著差别。在雨季晴天自然条件下, 午间最高光强可 达 $2200 \mu \mathrm{mol} \mathrm{m}{ }^{-2} \mathrm{~s}^{-1}$ 以上, 最高叶温比气温高 $7 \sim 8{ }^{\circ} \mathrm{C}$, 而成熟叶片的最高温度比全展嫩叶高 $1.5 \sim 2{ }^{\circ} \mathrm{C}$ 。上午随 光强的增大, 两种叶片的非光化学猝灭系数 (NPQ)增大, PS II 原初光化学效率 $(F v / F m)$ 、实际光化学效率 $\left[\left(F^{\prime}\right.\right.$ $F s) / F m^{\prime}$ ] 逐渐减小, 在 15:30 左右达最小。下午随着光强的减弱, $F v / F m$ 逐渐恢复, 在傍晚基本恢复到清晨值。初 始苂光 $\left(F_{0}\right)$ 在一天中变化很小。这表明线毛番龙眼叶片光抑制是非辐射能量耗散增加引起的保护光合机构免受 光破坏的保护性反应, 而非光破坏。全展嫩叶比成熟叶有较低的光化学效率和非辐射耗散能力, 对强光和高温处 理的敏感性也较强, 但在自然条件下一天中的光抑制程度与成熟叶没有显著差别。田间午间强光导致两种叶片的 保护酶活性(超氧化物歧化酶 SOD 抗坏血酸过氧化物酶, APX) 升高, 而 $\mathrm{H}_{2} \mathrm{O}_{2}$ 含量变化较小。其中, 全展嫩叶的保 护酶活性高, 丙二醛 (MDA) 含量低。这表明自然条件下, 与成熟叶相比, 线毛番龙眼全展嫩叶通过较低的光能利用 效率、较低的叶温和高的保护酶活性减轻了强光高温的光抑制程度。
\end{abstract}

关键词 线毛番龙眼 完全伸展嫩叶 成熟叶 光抑制 菼光参数

\section{PHOTOINHIBITION OF PHOTOSYNTHESIS IN LEAVES OF TWO DEVELOPING STAGES OF A TROPICAL RAINFOREST CANOPY TREE , POMETIA TOMENTOSA}

\author{
CAI Zhi-Quan CAO Kun-Fang and QI Xin \\ (Xishuangbanna Tropical Botanical Garden, the Chinese Academy of Sciences, Mengla, Yunnan 666303 , China)
}

\begin{abstract}
Pometia tomentosa, is a dominant uppermost canopy tree and a symbol species of vallyland forest in Xishuangbanna tropical rainforest. In addition to anatomical and physiological characteristics, diurnal changes in chlorophyll fluorescence parameters were measured with a modulated chlorophyll fluorescence monitoring system (FMS2) in order to explore the difference of diurnal photoinhibition in leaves of two developing stages, young fully expanded leaves and mature leaves of Pometia tomentosa in the rainy season. The difference in the effect of midday strong light and high temperature on the activities of partly protective enzymes was also briefly analyzed. The results showed : leaf thickness, chlorophyll contents, stomatal conductance, carboxylation efficiency, maximum net photosynthetic rate and light saturation point of mature leaves were much higher than those of young fully expanded leaves , while the stomatal density and guard cell length were similar between two leaves. On clear days in the rainy season, the highest photon flux density can exceed $2200 \mu$ mol $\cdot \mathrm{m}^{-2} \mathrm{~s}^{-1}$, the highest leaf temperature was $7-8{ }^{\circ} \mathrm{C}$ higher than air temperature , and the highest leaf temperature of mature leaves was $1.5-2{ }^{\circ} \mathrm{C}$ higher than that of young fully expanded leaves. Non-photochemical quenching (NPQ) was increased, the initial photochemical efficiency $(F v / F m)$ and actual photochemical efficiency [ $\left.\left(F m^{\prime}-F s\right) / F m\right]$ decreased gradually in the morning, and reached the lowest values at about 15:30. The reverse changes occurred in the afternoon, at dusk these parameters could recover to nearly the original dawn level. The decrease in $F v / F m$ was mainly caused by a decrease in $F m$, because initial fluorescence $\left(F_{0}\right)$ did not change significantly over the course of the day. This suggested that the photoinhibition observed
\end{abstract}


in Pometia tomentosa was due to photoprotective process and not to photoinhibitory damage. The initial photochemical efficiency $(F v / F m)$ of young fully expanded leaves was lower than that of mature leaves , and exhibited more sensitive to strong light and high temperature treatment , but their diurnal photoinhibition was statistically similar in the field. After field strong light at midday the protective enzymes (SOD , APX) increased , while $\mathrm{H}_{2} \mathrm{O}_{2}$ content was stable and the lipid peroxide level was lower in young expanded leaves compared with mature leaves. We concluded that the alleviated photoinhibition in young expanded leaves might be caused by its lower photochemical efficiency and leaf temperature, as well as active protection by higher activities of protective enzymes under the field conditions.

Key words Pometia tomentosa , Young fully expanded leaves ,Mature leaves , Photoinhibition , Chlorophyll fluorescence parameters

光抑制是指植物光合机构所吸收的光能超过 其所利用的限度时，引起 PS II 过量激发,造成光合 能力的下降，即光能转换效率的降低 (Long et al. ， $1994 ;$; Osmond , 1994) 的现象。长期光抑制不仅影响 到森林生态系统的生产力, 同时对植物的不利影响 可能会限制其在自然界的适应与生存 (Long et al. , 1994)。不同植物、同一植物不同发育阶段的叶片对 强光的敏感性不同。为了避免强光引起的光破坏, 叶黄素循环、Mehler 反应、光呼吸及通过叶片运动以 减小光能吸收等都是植物保护光合机构的有效措施 (Demmig-Adams \& Adams , 1992)。

在自然条件下, 晴天中午植物上层叶片常常发 生光抑制(许大全等, 1990)。对自然条件下农作物 (孟庆伟等,1996 郭连旺等,1996)、灌木(郭连旺等， 1994 ;陶汉之 ,1991)、小乔木(Damatta et al 。, 1997 ; 孟 庆伟等, 1999)的光抑制已有大量的研究, 但对热带 雨林冠层植物光抑制的研究不多 (Gamon \& Pearcy, 1989 ;Krause et al. ，1995），特别是在热带典型的自 然强光和高温季节对冠层树种不同发育阶段叶片的 光抑制少见报道。雨季是热带雨林植物能物流交 换、生长、发育最佳季节(吴邦兴,1991)，而在这个时 期内, 冠层树种上层叶片常常暴露于强光下, 这时如 果不能有效启动体内能量耗散机制的运转, 就容易 导致光合机构的光破坏，从而影响植物的适应、更新 和分布。线毛番龙眼 (Pometia tomentosa) 是西双版 纳热带雨林常见的上层树种, 也是该地区沟谷雨林 的一个标志种 (吴征镒等, 1987)。本研究选择线毛 番龙眼冠层两种不同发育阶段叶片 (全展嫩叶和成 熟叶) 为实验材料, 研究其在雨季晴天的光抑制, 初 步探讨以下问题: 1) 完全伸展嫩叶和成熟叶的形态 解剖和光合特征的差异，2)两种叶片在雨季自然状 况下菼光参数的日变化和光抑制;3) 午间强光对保 护酶(SOD,APX) 活性和膜脂过氧化的影响;4)两种 叶片的光合反应中心 PS II 对强光和高温敏感性的 差异。

\section{1 材料和方法}

\section{1 测定地点和实验材料}

研究地点在西双版纳热带植物园葫芦岛沟谷林 内的观测铁塔上进行地理位置为 $21^{\circ} 50^{\prime} \mathrm{N}, 101^{\circ} 12^{\prime}$ $\mathrm{E}$ 海拔约 $600 \mathrm{~m}$ 。属北热带季风气候, 年平均降雨 量 $1557 \mathrm{~mm}$,全年干湿季分明。土壤为砖红壤, 土层 深厚, 水分充足。

研究材料选择定位研究所建的气象铁塔旁的一 株线毛番龙眼 (Pometia tomentosa)。线毛番龙眼叶 片为偶数羽状对生复叶, 当年生小枝上叶片的叶面 积特点如图 1。由于自植株顶部下数的第四对叶叶 面积最大，与一年生成熟叶片(第五、六对)的叶面积 没有显著差异, 所以选择这对叶作为完全伸展嫩叶 (叶龄大约为 $20 \mathrm{~d}$ ) 和一年生枝上中部叶 (成熟叶) 为 实验对象。观测叶片均为 $25 \mathrm{~m}$ 处植株顶层水平伸 展阳生叶。西双版纳为有名的静风区，观测日无大 风, 有轻微风时用薄泡沫夹住叶柄以防摇动。测定 时间为 9 月 22 日、27日和 28 日，时期正值雨季 (5 月至 10 月）,占年降雨量 $83 \%$ 。月最高温度 30.2 ${ }^{\circ} \mathrm{C}$, 最低温度 $21.3{ }^{\circ} \mathrm{C}$ 。

\section{2 环境因子和叶片光合特性的测定}

用连接数据采样器 (LICOR1400) 上的光量子探 头测定一天中 7:00 19:00 的光因子, 每 $15 \mathrm{~s}$ 计数 1 次。气孔导度由 $\mathrm{AP} 4$ 气孔计在观测铁塔上测定连 体叶片。用 LICOR-6400 光合作用分析系统测定离 体叶片 (测定过程中枝条基部始终浸没在水中) 的 光合响应曲线(温度 $(25 \pm 0.2){ }^{\circ} \mathrm{C}, \mathrm{CO}_{2}$ 浓度 $(380 \pm$ 12.5) $\mu \mathrm{mol} \mathrm{mol}{ }^{-1}$ ) 和 $\mathrm{CO}_{2}$ 响应曲线(温度 $(25 \pm 0.2)$ ${ }^{\circ} \mathrm{C}$, 光照 $\left.1000 \mu \mathrm{mol} \mathrm{m} \mathrm{m}^{-2} \mathrm{~s}^{-1}\right)$, 羧化效率由低胞间 $\mathrm{CO}_{2}$ 浓度下直线的斜率所得。

用便携式脉冲调制荧光仪 FMS-2 (英国 Hansat$e c h$ 公司) 测定叶绿素 a 苂光参数的日变化。叶片暗 适应 $15 \mathrm{~min}$ 后, 用弱测量光测定初始荧光 $\left(F_{0}\right)$, 随 后给一个强闪光 $\left(5000 \mu \mathrm{mol} \mathrm{m} \mathrm{m}^{-2} \mathrm{~s}^{-1}\right.$,脉冲时间 0.7 
$\mathrm{s})$ 测得最大苂光 $F m$, 当苂光产量从 $F m$ 降到 $F_{0}$ 时, 打开作用光 ( $\left.400 \mu \mathrm{mol} \mathrm{m}^{-2} \mathrm{~s}^{-1}\right)$, 苂光恒定时 测得稳态苂光 (Fs), 加上一个强闪光 (5000 $\mu \mathrm{mol}$ $\mathrm{m}^{-2} \mathrm{~s}^{-1}, 0.7 \mathrm{~s}$ ) 后测定 $F m^{\prime}$, 关闭作用光使叶片暗 适应 $3 \mathrm{~s}$ 后, 打开远红光, $5 \mathrm{~s}$ 后测定最小苂光 $\left(F_{0}{ }^{\prime}\right)$ 。光系统 II (PS II ) 光化学效率 $F v / F m$ 、实际 光化学效率 $\left(F m^{\prime}-F s\right) / F m^{\prime}$ 、非光化学猝灭系数 $\mathrm{NPQ}=F m / F m^{\prime}-1$ ( Fm 用清晨值) 由仪器自动给出, PS II 电子传递速率用公式 ETR $=\left(F m^{\prime}-F s\right) / F m^{\prime} \times$ $\mathrm{PFD} \times 0.84 \times 0.5$ 计算, PFD 为叶面入射光 $($ Maxwell \& Johnson ,2000)。同时用苂光仪上的温度感应探头 测定叶温和环境空气温度。叶绿素苂光响应曲线的 测定参照 Brodribb 和 Hill (1997) 的方法测定离体叶 片, 每种光强下平衡 15 min。

叶片对强光和温度敏感性的观测 : 在上午直射 光照到叶片之前, 将枝条剪下, 测定叶片的苂光指 标 然后用灯光 $\left(1800 \mu \mathrm{mol} \mathrm{m} \mathrm{m}^{-2} \mathrm{~s}^{-1}\right)$ 照射离体叶 片 $1.5 \mathrm{~h}$ (灯与叶片之间有流动的隔热水层, 温度 $\left.(25 \pm 1)^{\circ} \mathrm{C}\right)$, 再在低光下 $\left(15 \mu \mathrm{mol} \mathrm{m}^{-2} \mathrm{~s}^{-1}\right)$ 恢复, 测定叶片的苂光指标。用离体叶圆片测定 $F v / F m$ 对温度的敏感性 叶室内为普通空气, 外加光强约 1 $800 \mu \mathrm{mol} \mathrm{m} \mathrm{m}^{-2} \mathrm{~s}^{-1}$ 。通过循环水的温度控制叶室内 叶片的温度, 每种温度下平衡 $30 \mathrm{~min}$ 。

\section{3 抑制剂的引入}

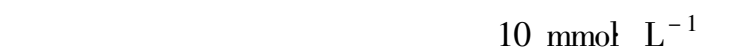
DTT( 二硫苏糖醇) 溶液中 弱光下 $\left(20 \sim 30 \mu \mathrm{mol} \mathrm{m} \mathrm{m}^{-2}\right.$ $\mathrm{s}^{-1}$ ) 放置 $1.5 \mathrm{~h}$, 使叶片吸入 DTT。对照叶片置于 蒸馏水中,与处理材料一同移到 $1800 \mu \mathrm{mol} \mathrm{m}^{-2}$ $\mathrm{s}^{-1}$ 光强处, 照射 $2 \mathrm{~h}$ (灯与叶片之间有流动的隔热水 层 温度 $\left.(25 \pm 1)^{\circ} \mathrm{C}\right)$ 。

\section{4 实验分析方法}

叶面积的测定用方格纸计数法。叶片形态解剖 在显微镜下观测, 叶片厚度由徒手切片观测, 气孔密
度由无色指甲油印迹观测。

叶绿素含量的测定参照 Arnon(1949) 的方法, 取一定重量的叶片, 剪碎, 用 $80 \%$ 的丙酮提取。

超氧化物歧化酶 (SOD) 活性的测定:取 $0.3 \mathrm{~g}$ 叶, 加入 $4 \mathrm{ml} 50 \mathrm{~mol} \mathrm{~L} \mathrm{~L}^{-1}$ ( $\mathrm{pH} 7.8$ ) 的磷酸缓冲液(内 含适量的 PVP)于冰浴上研磨, 于 $12000 \times g 、 4{ }^{\circ} \mathrm{C}$ 离 心 $15 \mathrm{~min}$,上清液为酶液。参照 Giannoplitis 和 Ries (1977)的方法 (略加修改), 定义单位时间内抑制 NBT 光化还原 $50 \%$ 为一个酶活性单位 $(U)$ 。

抗坏血酸过氧化物酶 (APX) 活性的测定按照沈 文威等(1996)的方法测定, 在 UV-1601 型紫外分光 光度计 (日本岛津公司) 上测定每分钟 $\mathrm{A}_{290}$ 的下降, 1 $\min$ 催化 $1 \mu \mathrm{mol}$ 的酶量为一个酶活性单位。

过氧化氢 $\left(\mathrm{H}_{2} \mathrm{O}_{2}\right)$ 含量的测定参照林植芳等 (1988)的方法。丙二醛 (MDA) 含量的测定参照王以 柔等(1986)的方法。

\section{2 结 果}

2.1 两种不同发育阶段叶的解剖和生理特性的比 较

表 1 表明了线毛番龙眼全展嫩叶和成熟叶的一 般解剖和生理特征。两种叶片以单位面积表示的叶 绿素含量有显著差异。全展嫩叶的厚度比成熟叶明 显小, 气孔导度和羧化效率较低, 而气孔密度和保卫 细胞长度没有差异。光合响应曲线表明成熟叶比全 展嫩叶有较大的净光合速率和较高的光饱和点 (图 2)。

2.2 不同田间环境条件下线毛番龙眼叶绿素荧光 参数的日变化

通过在不同田间环境条件下，对线毛番龙眼叶 绿素苂光参数测定, 发现连续 3 天菼光参数的测定 结果相似, 图 3 是其中一天的情况。雨季晴天的午 间最大光强可达 $2200 \mu \mathrm{mol} \mathrm{m} \mathrm{m}^{-2} \mathrm{~s}^{-1}$ 以上, 最高空

表 1 全展嫩叶和成熟叶的解剖特征和一些生理特征的比较

Table 1 Comparisons of the anatomy and physiological characteristics between young fully

expanded leaves (FEL) and mature leaves (ML) of Pometia tomentosa

\begin{tabular}{|c|c|c|c|c|c|c|c|}
\hline $\begin{array}{c}\text { 叶片发育阶段 } \\
\text { Leaf developing } \\
\text { stage }\end{array}$ & $\begin{array}{c}\text { 厚度 } \\
\text { Thickness } \\
(\mu \mathrm{m})\end{array}$ & $\begin{array}{c}\text { 气孔密度 } \\
\text { Stomata density } \\
\left(\text { Number } \mathrm{mm}^{-2}\right)\end{array}$ & $\begin{array}{c}\text { 保卫细胞长度 } \\
\text { Guard cell length } \\
(\mu \mathrm{m})\end{array}$ & $\begin{array}{r}\text { 叶绿素含量 } \\
\text { Chl content } \\
\left(\mu \mathrm{g} \mathrm{cm}^{-2}\right)\end{array}$ & $\begin{array}{c}\text { 叶绿素 } \mathrm{a} / \mathrm{b} \text { 比值 } \\
\mathrm{Chl} \mathrm{a/b} \text { ratio }\end{array}$ & $\begin{array}{c}\text { 气孔导度 } \\
\mathrm{Gs} \\
\left(\mathrm{mmol} \mathrm{m} \mathrm{m}^{-2} \mathrm{~s}^{-1}\right)\end{array}$ & $\begin{array}{c}\text { 羧化效率 } \\
\text { CE } \\
\left(\mathrm{mol} \mathrm{mol}^{-1}\right)\end{array}$ \\
\hline $\begin{array}{c}\text { 全伸展嫩叶 Fully expanded } \\
\text { leaves (FEL) }\end{array}$ & $\begin{array}{l}254.3 \mathrm{a} \\
(23.4)\end{array}$ & $\begin{array}{c}319.5 \mathrm{a} \\
(18.5)\end{array}$ & $\begin{array}{l}16.1 \mathrm{a} \\
(3.1)\end{array}$ & $\begin{array}{l}17.2 \mathrm{a} \\
(3.5)\end{array}$ & $\begin{array}{l}2.14 \mathrm{a} \\
(0.32)\end{array}$ & $\begin{array}{l}178 \mathrm{a} \\
(24.5)\end{array}$ & $\begin{array}{l}0.028 \mathrm{a} \\
(0.011)\end{array}$ \\
\hline $\begin{array}{c}\text { 成熟叶 Mature leaves } \\
\text { (ML) }\end{array}$ & $\begin{array}{l}312.1 \mathrm{~b} \\
(16.7)\end{array}$ & $\begin{array}{c}332.1 \mathrm{a} \\
(23.4)\end{array}$ & $\begin{array}{l}16.7 \mathrm{a} \\
(2.7)\end{array}$ & $\begin{array}{c}49.6 \mathrm{~b} \\
(4.6)\end{array}$ & $\begin{array}{l}3.12 \mathrm{~b} \\
(0.21)\end{array}$ & $\begin{array}{l}245 \mathrm{~b} \\
(32.3)\end{array}$ & $\begin{array}{l}0.045 \mathrm{~b} \\
(0.008)\end{array}$ \\
\hline & $p<0.01$ & NS & NS & $p<0.05$ & $p<0.05$ & $p<0.01$ & $p<0.05$ \\
\hline
\end{tabular}

Gs : Stomatal conductance CE : Carboxylation efficiency 括号里的数据为标准差 The data in parentheses are the standard error $(n=3) \quad *$ 上午 11 时测定 Measurements were carried out at 11:00 NS : 无显著差异 Non-significance 


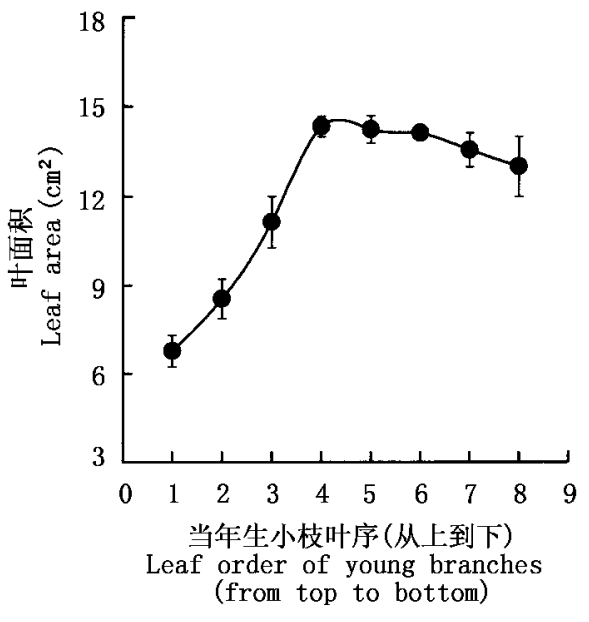

图 1 线毛番龙眼当年生小枝上叶片的叶面积特征

Fig. 1 The characteristics of leaf area in young branches of Pometia tomentosa

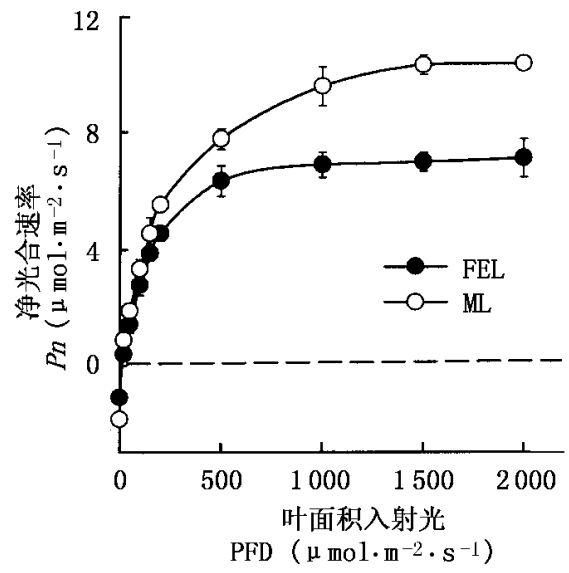

图 2 线毛番龙眼叶片的净光合速率对光强的响应

Fig.2 The response of net photosynthesis to light intensity in leaves of Pometia tomentosa (means $\pm \mathrm{SD}, n=2$ )

FEL : 全展嫩叶 Young fully expanded leaves ML : 成熟叶 Mature leaves

气温度可达 $33{ }^{\circ} \mathrm{C}$, 而最大叶温比气温高 $7 \sim 8{ }^{\circ} \mathrm{C}$, 成 熟叶比全展嫩叶高 $1.5 \sim 2{ }^{\circ} \mathrm{C}$ 。早晚相对湿度都在 $90 \%$ 以上 ,中午最低湿度也大于 $60 \%$ (图 3A) , 这是 雨季热带地区典型的强光、高温和高湿天气。

全展嫩叶清晨的 $F v / F m$ 值明显比成熟叶小 $(p$ $<0.01)$ 。上午随着光强的增大，两种叶片的苂光参 数 $F v / F m 、\left(F m^{\prime}-F s\right) / F m^{\prime} 、 F m$ 减小, $F_{0}$ 变化不 大(图 3B、C、D) ,NPQ 增大(图 3E)。其中，成熟叶的 最大光化学效率 $F v / F m$ 和实际光化学效率 $\left(F m^{\prime}-\right.$ $F s) / F m^{\prime}$ 比全展嫩叶的大, 说明成熟叶在自然状况 下比伸展叶有较大的光能利用能力。全展嫩叶的 $F_{0}$ 比成熟叶低,这可能与它的叶绿素含量较低有 关。一天中 , $F_{0}$ 变化较小, $F m$ 减小是 $F v / F m$ 降低

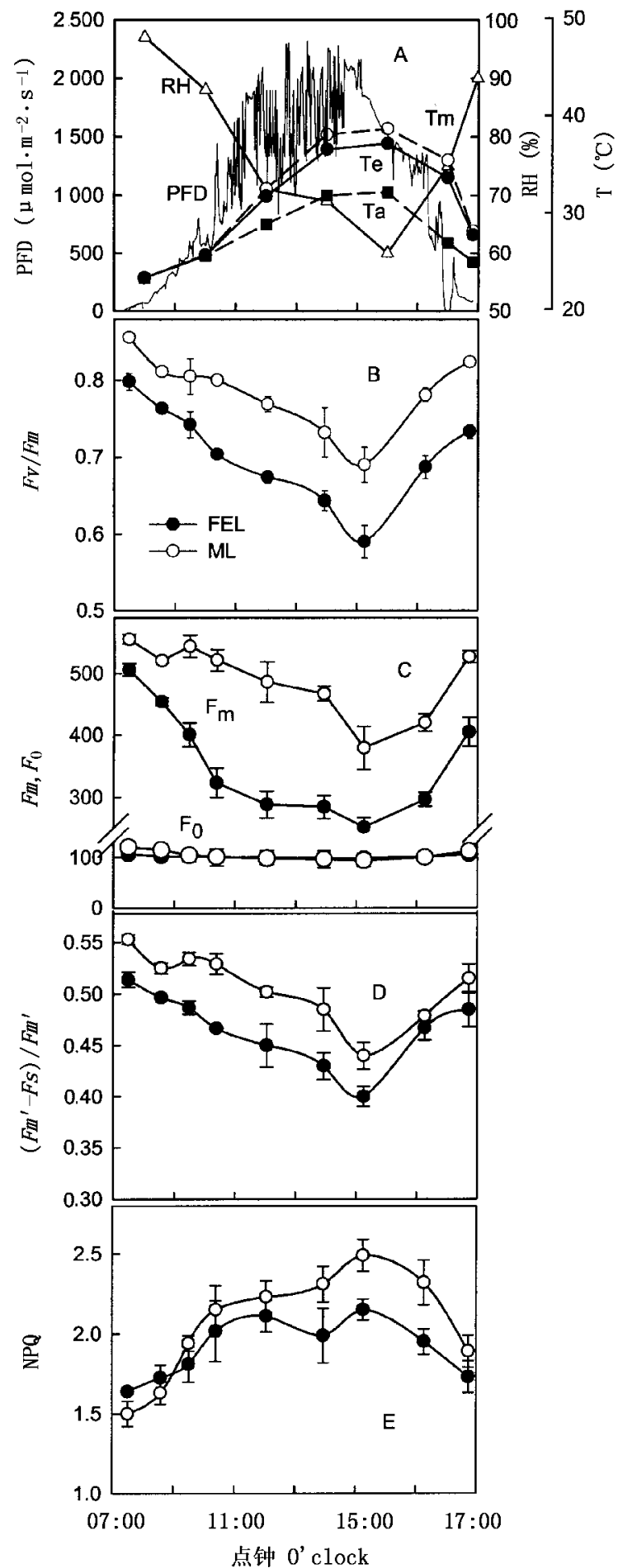

图 3 不同田间环境条件下线毛番龙眼叶片苂光 参数的日变化 (2001-09-28)

Fig. 3 Diurnal changes of chlorophyll fluorescence parameters (means \pm SD , $n=3$ ) in leaves of Pometia tomentosa (September 28,2001 ) under different field environmental conditions

RH 相对湿度 Relative humidity $\mathrm{Tm}$ : 成熟叶的温度 Temperature of mature leaves $\mathrm{Te}$ : 全展嫩叶温度 Young fully expanded leaves $\mathrm{Ta}$ : 空气温度 Air temperature NPQ : 非光化学猝灭系数 Non-photochemical quenching FEL、ML : 同图 2 See Fig. 2

的主要原因。而成熟叶非光化学猝灭系数 NPQ 在 上午低光时 $\left(<400 \mu \mathrm{mol} \mathrm{m}^{-2} \mathrm{~s}^{-1}\right)$ 比全展嫩叶小， 
但在高光下上升较快。午间约 $4 \mathrm{~h}$ 的强光照射后, 全展嫩叶和成熟叶的光化学效率 $F v / F m$ 分别比清 晨下降了 $17.6 \% 、 18.1 \%$ ，下降的比率没有显著差 异 $(p>0.05)$,傍晚 7:00 左右线毛番龙眼两种叶片 $\mathrm{Fv} / \mathrm{Fm}$ 都恢复到清晨值的 $95 \%$ 以上。

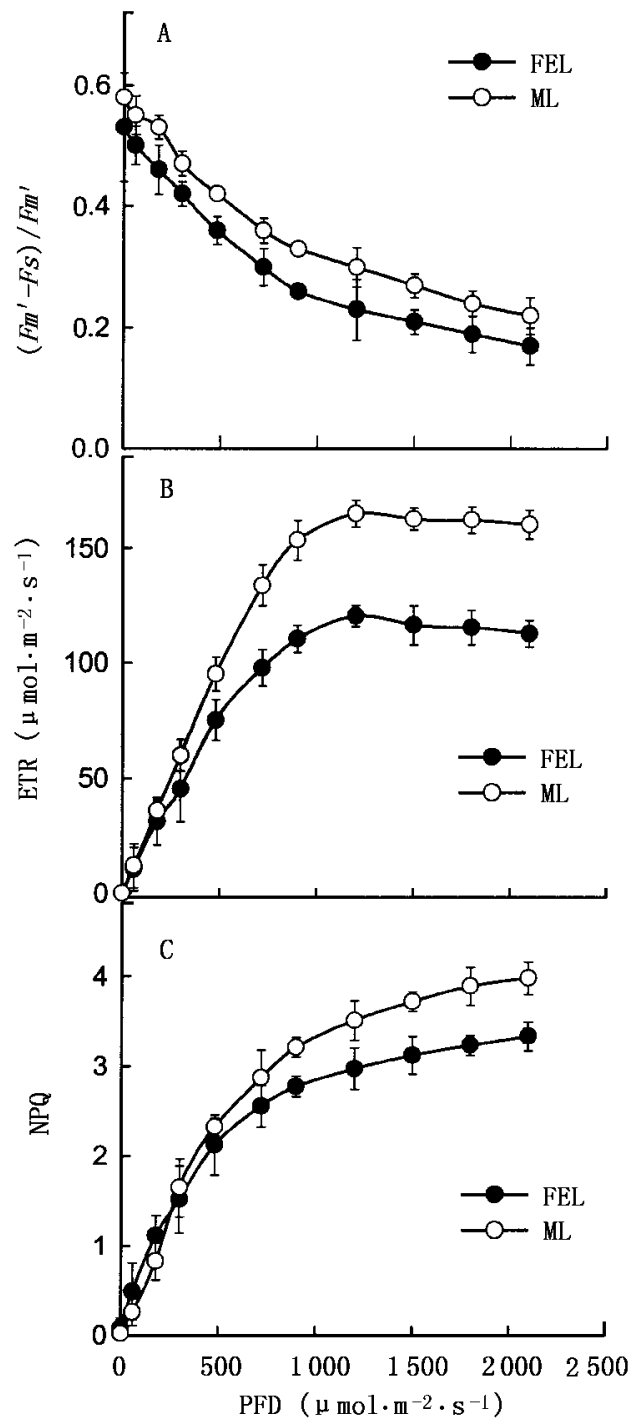

图 4 线毛番龙眼叶片苂光参数对光强的光响应曲线

Fig.4 The response of actual quantum yield $\left[\left(F^{\prime}-F s\right) / F m^{\prime}\right]$,

apparent electron transport rate (ETR) and non-photochemical quenching (NPQ) to photon flux density

(PFD) in the leaves of Pometia tomentosa

( means $\pm \mathrm{SD}, n=2$ )

FEL、ML : 同图 2 See Fig. 2

适宜温度下的苂光响应曲线表明: 在一定的光 强下, 全展嫩叶的实际光化学效率 $\left(F m^{\prime}-F s\right)$ / $F m^{\prime}$ 、电子传递速率 ETR 值和非光化学猝灭系数 NPQ 比成熟叶的小 (图 4A、B、C)，这表明冠层成熟叶 的光能利用能力比伸展叶的大, 非辐射耗散过剩光 能的能力也强。

2.3 田间午间强光对部分保护酶活性和叶片膜脂
过氧化的影响

午间强光和高温后，线毛番龙眼两种叶片保护 酶 SOD、APX 活性仍有所升高(图 5A)。其中, 全展 嫩叶和成熟叶的 SOD 活性增大到原来的 1.5、1.4 倍, 全展嫩叶的 APX 活性比成熟叶高, 午后分别增 大到原来的 $1.8,1.2$ 倍。两种叶片 $\mathrm{H}_{2} \mathrm{O}_{2}$ 的含量变 化不大, 而成熟叶的 MDA 含量比全展嫩叶稍高, 午 后全展嫩叶的 MDA 含量变化不大, 而成熟叶的 $\mathrm{MDA}$ 含量有所上升(图 5B)。
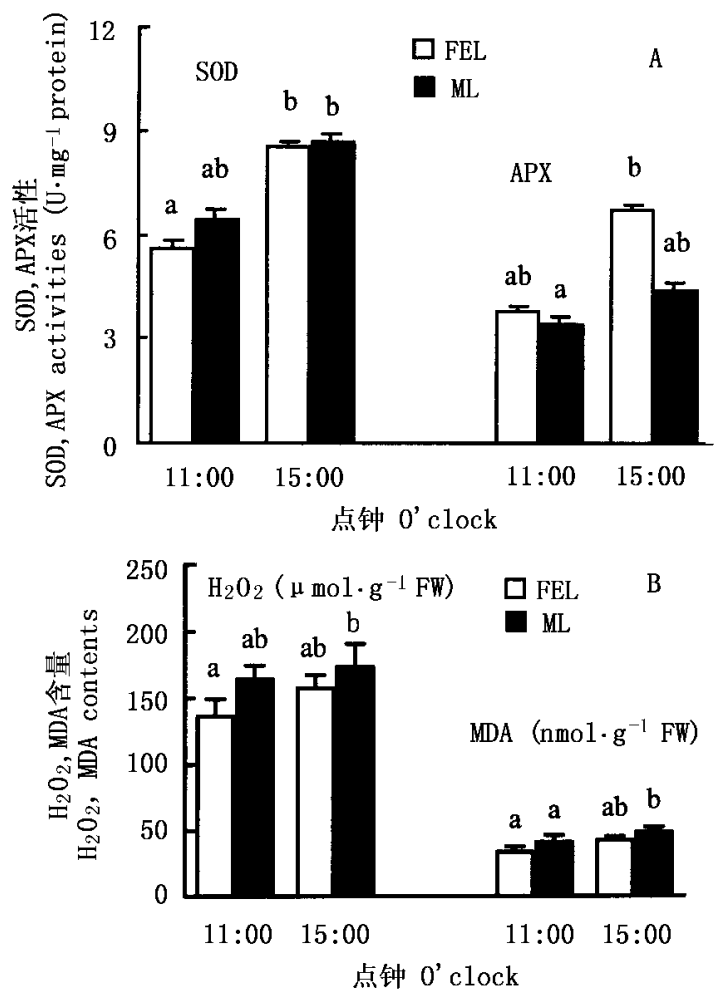

图 5 田间午间强光对保护酶 (SOD,APX)活性和 膜脂过氧化作用的影响

Fig.5 The effects of filed strong light in midday on the activities of protective enzymes (SOD , APX) and lipid peroxide in young fully expanded leaves and mature leaves FEL、ML : 同图 2 See Fig. 2

2.4 DTT 对线毛番龙眼光抑制的影响以及两种发 育阶段的叶片对强光和温度敏感性的差异

$1.5 \mathrm{~h}$ 的强光照射使全展嫩叶和成熟叶的光化 学效率 $F v / F m$ 分别下降了 $8.5 \% 、 7.9 \%$,而强光下 用 DTT 处理使其苂光参数 $F v / F m$ 分别下降了 $15.2 \% 、 18.9 \%$ (图 6)。与单一强光照射相比, DTT 处理显著降低了线毛番龙眼叶片的 $F v / F m$ 值, 这表 明抑制玉米黄质的形成后光抑制程度加重, 成熟叶 抑制的程度比全展嫩叶大。

一定温度下 $\left(25{ }^{\circ} \mathrm{C}\right)$ 经强光照射 $1.5 \mathrm{~h}$ 后, 两种 不同类型的叶片光化学效率均呈下降趋势 (图 7)。 
其中，全展嫩叶的光化学效率下降了 $12.3 \%$,而成 熟叶下降了 $10.8 \%$,两种叶片下降的比率存在显著 差异 $(p<0.05)$ 。在弱光下恢复 $4 \mathrm{~h}$ 后, 成熟叶恢复 到原初值的 $95.8 \%$, 而伸展叶只恢复了 $91.7 \%$ 。全 展嫩叶经强光照射下降的比率较大, 在弱光下恢复 慢, 说明全展嫩叶对强光比成熟叶敏感。

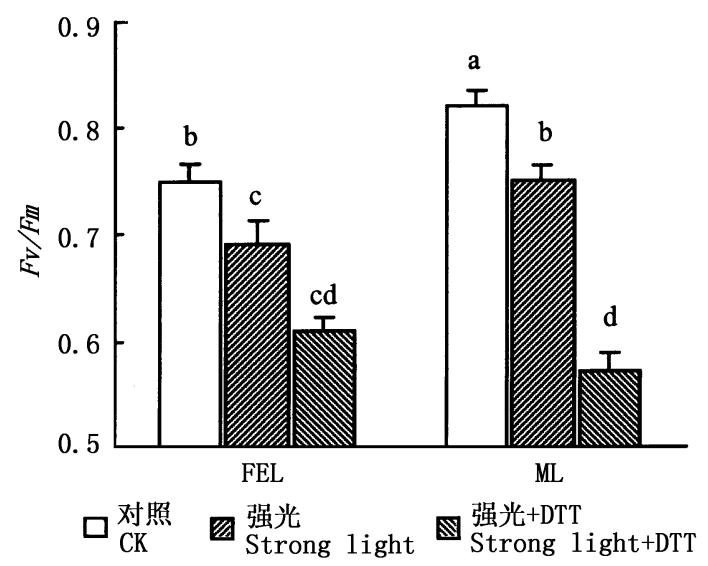

图 6 强光和 DTT 处理对线毛番龙眼 PS II 光化学效率的影响

Fig.6 The effect of strong light $\left(1800 \mu \mathrm{mol} \mathrm{m} \mathrm{m}^{-2} \mathrm{~s}^{-1}\right)$ and DTT on the photochemical efficiency $(F v / F m)$ in the leaves of Pometia tomentosa (means $\pm \mathrm{SD}, n=3$ ) FEL、ML : 同图 2 See Fig. 2

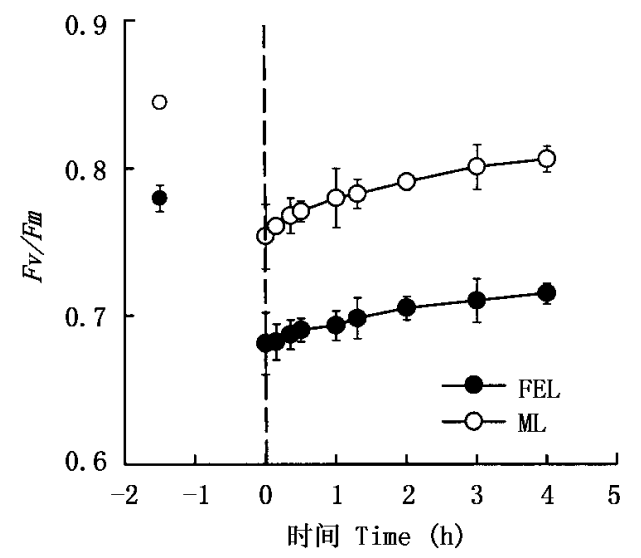

图 $71.5 \mathrm{~h}$ 强光处理对线毛番龙眼离体叶片光抑制程度 及在弱光下恢复的影响

Fig.7 The effects of $1.5 \mathrm{~h}$ strong light $\left(1800 \mu \mathrm{mol} \mathrm{m} \mathrm{m}^{-2} \mathrm{~s}^{-1}\right)$ treatment on photoinhibition and its recovery in weak light $\left(15 \mu \mathrm{mol} \mathrm{m} \mathrm{m}^{-2} \mathrm{~s}^{-1}\right)$ in detached leaves of Pometia tomentosa (means $\pm \mathrm{SD}, n=3$ ) FEL、ML : 同图 2 See Fig. 2

强光下线毛番龙眼两种叶片光化学效率的适应 温度为 $25{ }^{\circ} \mathrm{C}$ 左右, 而在 $37{ }^{\circ} \mathrm{C}$ 高温下, 成熟叶和全展 嫩叶的光化学效率分别比 $25{ }^{\circ} \mathrm{C}$ 时降低了 $7.9 \%$ 、 $12.6 \%$ 。再增加 $3{ }^{\circ} \mathrm{C}$ 时, 成熟叶的光化学效率又降低 了 $1.5 \%$,全展嫩叶则降低了 $4.7 \%$ (图 8)。在高温 下全展嫩叶的光化学效率下降的比率大, 说明全展 嫩叶对高温更为敏感。

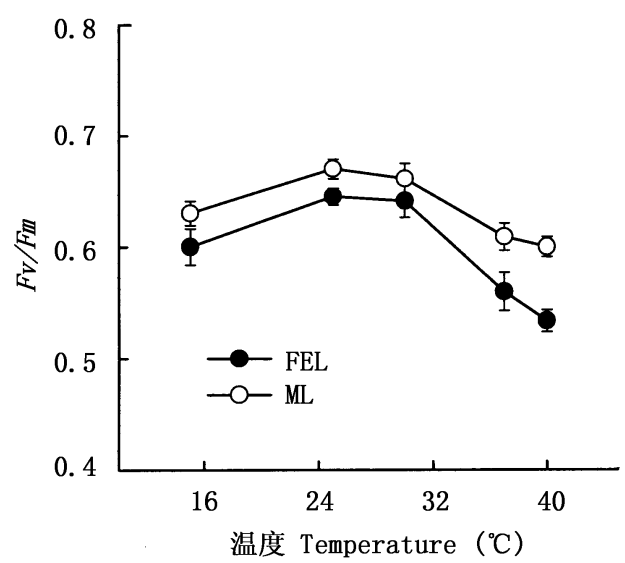

图 8 不同温度下强光对线毛番龙眼离体叶片光化学效率的影响 Fig. 8 The effects of temperature on photochemical efficiency in detached leaves of Pometia tomentosa were exposed to strong light (1 $800 \mu \mathrm{mol}$ $\mathrm{m}^{-2} \mathrm{~s}^{-1}$ ) under various temperatures (means $\pm \mathrm{SD}, n=2$ ) FEL、ML : 同图 2 See Fig. 2

\section{3 讨 论}

3.1 线毛番龙眼两种不同发育阶段叶片的光抑制 在热带森林里, 有很多植物叶片捕光系统在叶 完全伸展后仍没有完成 (Kursar \& Coley，1992)。延 缓变绿 (Delayed greening) 是很多植物叶片发育的典 型特征, 延缓变绿叶的叶绿素和 1,5 -二磷酸核酮糖 羧化氧化酶 (Rubisco) 含量仅是普通绿叶的 $10 \%$ 20\% (Kursar \& Coley , 1995)。线毛番龙眼全展嫩叶 的叶面积与成熟叶没有差别, 而叶绿素含量仅为成 熟叶的 $1 / 3$ 。另外 翔化效率的大小是叶片中 Rubisco 含量多少的指标 (Farquhar \& Sharkey，1982) ,全展 嫩叶羧化效率低说明叶片中活化的 Rubisco 量小, 可 见线毛番龙眼全展嫩叶表现出延缓变绿现象。同 时, 成熟叶羧化效率高说明光合作用的羧化限制程 度小, 而气孔密度和保卫细胞长度没有区别, 气孔导 度高 其光合速率也较高(表 1 , 图 2) ,说明气孔导度 是其光合作用有所区别的另一重要限制因素。

光化学效率 $(F v / F m)$ 降低是光抑制最明显的 特征之一 (Osmond, 1994)。上午随光强的增加, 线 毛番龙眼叶片 $\mathrm{Fv} / \mathrm{Fm}$ 降低。雨季晴天中午光强远 远高于叶片光合作用的饱和光强 (成熟叶约 1650 $\mu \mathrm{mol} \mathrm{m} \mathrm{m}^{-2} \mathrm{~s}^{-1}$ ), 过剩光能使 $F v / F m$ 降低, 在 $15: 30$ 左右达到最低点, 表明光系统 II 的功能发生了光抑 制。光抑制的发生可能是光合机构遭受过量光能破 坏的结果 (Baker, 1991) , 也可能是保护光合机构免 于破坏的保护性反应( Osmond，1994;Demmig-Adams \& Adams ,1992)。一般认为自然条件下, 植物的多种 保护机制可能足以防止光合机构反应中心发生明显 的破坏 (Demmig-Adams \& Adams , 1992 ;Long et al. ， 
1994 ) 光化学效率整夜未恢复的现象很少见( Krause et al . , 1995 ;Lovelock et al. ,1994) 线毛番龙眼也不 例外, 即使经过雨季午间强光高温的环境, 其发生光 抑制的机理仍可能是以非辐射能量耗散为主。因为 一天中两种不同发育阶段叶片 $F_{0}$ 变化很小, 光系 统 II 的光化学效率 $F v / F m$ 在下午随光强的减弱和 温度的降低均升高，光抑制得到缓解，在 19:00 时基 本恢复 (图 3B), 表明光合器官没有受到明显的光氧 化破坏。可见 线毛番龙眼叶片光合作用的光抑制 是保护光合机构免于破坏的保护性反应。

在除光以外没有其它胁迫因子同时存在的自然 条件下,依赖叶黄素循环的非辐射能量耗散的增加 可能是大多植物主要的保护机制 (Demmig \& Adams , 1992 , 许大全等, 1992; 郭连旺等,1994)。叶绿素荧 光检测的非光化学猝灭系数 NPQ 与非辐射能量耗 散速度常数成比例, 并与玉米黄质的含量密切相关

(Demmig-Adams et al ., 1990 ;Brugnoli et al .,1998)。 清晨线毛番龙眼两种叶片 NPQ 最低, 随光强的增 大 ,NPQ 升高, 表明一天当中叶片通过热耗散消耗掉 的光能逐渐增加。用玉米黄质形成的专一抑制剂 DTT (Demmig-Adams et al. ,1990) 处理离体叶片时， 光抑制程度明显增大 (图 6)，表明依赖叶黄素循环 在防止光合机构的破坏中起重要作用。其中,成熟 叶的 NPQ 值大(图 3E , 图 4C) ,DTT 处理时光抑制程 度加重(图 5 ), 这可能与其较高的玉米黄质含量有 关。而在上午低光强时全展嫩叶的 NPQ 较大 (图 $3 \mathrm{E}$, 图 $4 \mathrm{C}$ ) 其原因需进一步探讨。

在实验条件下, 全展嫩叶比成熟叶对强光和高 温的敏感性强(图 7 , 图 8), 特别在较高温度下轻微 的升温明显加剧了强光下的光抑制(图 8)。而自然 条件下, 全展嫩叶和成熟叶的光抑制程度相似。这 可能与伸展叶叶绿素含量低、颜色浅有关, 浅颜色限 制叶温的升高(图 3A) (Tardy et al，，1998)而导致自 然条件下低的叶温，对其光抑制可能起保护作用。

3.2 自然条件下的两种叶片保护酶的反应和膜脂 过氧化作用

$\mathrm{O}_{2}^{-}$的产生是光合电子传递的必然结果 (Asada， 1999)。SOD 是叶绿体中清除 $\mathrm{O}_{2}^{-}$的主要酶, SOD 活 性与植物抗逆性密切相关, 它对植物叶片光合作用 具有保护作用(邹琦等, 1995)。植物体内 SOD 活性 随细胞内 $\mathrm{O}_{2}^{-}$浓度的增加而增加已为很多实验所证 实(Bowler et al . 1992)。即使经过自然条件下午间 强光和高温, 线毛番龙眼叶片 SOD 活性仍有所升 高, 间接表明了细胞内 $\mathrm{O}_{2}^{-}$水平的提高 (图 5A)，同
时又是 Mehler 反应运转加强的体现。SOD 清除 $\mathrm{O}_{2}^{-}$ 的同时会产生 $\mathrm{H}_{2} \mathrm{O}_{2}$, 它是光合作用的抑制剂, 如不 及时清除, 在很短时间内就会抑制光合作用。APX 是植物叶绿体中清除 $\mathrm{H}_{2} \mathrm{O}_{2}$ 的关键酶 (Neubauer \& Yamamoto，1992)。午后线毛番龙眼全展嫩叶 APX 酶活性升高,成熟叶 APX 酶也维持较高的活性, 而 $\mathrm{H}_{2} \mathrm{O}_{2}$ 含量变化较小 (图 5B), 这表明 APX 活性升高 清除了一部分 $\mathrm{H}_{2} \mathrm{O}_{2}$ 。 $\mathrm{H}_{2} \mathrm{O}_{2}$ 的产生和分解是植物叶 绿体对过剩光能的一种重要耗散过程 (Schreiber et al , 1995;Fryer et al .,1998) ,它作为一个减轻光抑 制损伤的反应而起作用。全展嫩叶叶绿素含量低， 捕光能力弱, 光化学效率低 (图 3D, 图 4A), 在高光 下形成的单线态氧少些, 同时它的保护酶活性较高 (图 5A), 因而受光破坏的可能性小, 其较少的膜脂 过氧化产物也可以说明这一点 (图 5B)。虽然 Mehler 反应被认为可起光保护作用 (Osmond \& Grace, 1995;Asada, 1999) ,但也有研究表明田间通过 Mehler 反应耗散过剩光能防御光破坏的作用是有限 的(陶宗娅等,2001; Wiese et al.,1998), 因此, 本研 究中田间线毛番龙眼叶片通过 Mehler 反应在耗散 过剩光能的方面是否起重要作用有待于进一步研 究。

综上所述，热带雨林冠层树种线毛番龙眼的全 展嫩叶和成熟叶表现出明显不同的解剖和生理特 性。在雨季强光高温的自然条件下, 两种不同发育 阶段叶片的光合作用都发生了明显的光抑制，这种 光抑制是非辐射能量耗散增加引起的保护光合机构 免受光破坏的结果。虽然全展嫩叶对强光和高温比 成熟叶敏感,但两种发育阶段叶片田间的光抑制程 度相似。全展嫩叶较低的光能利用效率、较低的叶 温和高的保护酶活性减轻了自然条件下强光和高温 的光抑制程度。

\section{参考 文 献}

Arnon, D. I. 1976. Copper enzymes in isolated polyphenol oxidase in Beta vulgaris. Planta, 24:1 15 .

Asada, K. 1999. The water-water cycle in chloroplasts: scavenging of active oxygens and dissipation of excess photons. Annual Review of Plant Physiology and Plant Molecular Biology, 50: 601 639.

Baker, N.R. 1991. A possible role for photosystem II in environmental perturbations of photosynthesis. Physiologia Plantarum, $81: 563 \sim 570$.

Bowler, C., M. V. Montagu \& D. Inze. 1992. Superoxiden dismutase and stress tolerance. Annual Review of Plant Physiology and Plant Molecular Biology, 43: $83 \sim 92$.

Brodribb, T.\& R.S. Hill. 1997. Light response characteristics of a morphologically diver group of southern hemisphere conifers as measured by chlorophyll fluorescence. Oecologia, 110: $10 \sim 17$. 
Brugnoli, E., A. Scartazza, C.D. Tullio, M.C. Monteverdi, M. Lauteri \& A. Augusti. 1998. Zeaxanthin and non-photochemical quenching in sun and shade leaves of $\mathrm{C}_{3}$ and $\mathrm{C}_{4}$ plants. Physiologia Plantarum, 104:727 734.

Damatta, F. M. , M. Maestri \& R.S. Barros. 1997. Photosynthetic performance of two coffee species under drought. Photosynthetica, 34: $257 \sim 264$.

Demmig-Adams, B., W.W. Adams III., U. Heber, S. Neimanis, K. Winter, A. Krüger, F. C. Czygan, W. Bilger \& O. Björkman. 1990. Inhibition of zeaxanthin formation and of rapid changes in radiationless energy dissipation by dithiothreitol in spinach leaves and chloroplast. Plant Physiology, 92:293 301 .

Demmig-Adams, B. \& W. W. Adams III. 1992. Photoprotection and other responses of plant to high light stress. Annual Review of Plant Physiology and Plant Molecular Biology, 43: 599 626.

Farquhar, S.P. \& T.D. Sharkey. 1982. Stomatal conductance and photosynthesis. Annual Review of Plant Physiology, 33: 317 345.

Fryer, M.J., J.R. Andrews, K. Oxborough, D. A. Blowers \& N. R. Baker. 1998. Relationship between $\mathrm{CO}_{2}$ assimilation, photosynthetic electron transport, and active $\mathrm{O}_{2}$ metabolism in leaves of maize in the field during periods of low temperature. Plant Physiology, 116:571 580.

Gamon, J. A. \& R. W. Pearcy. 1989. Leaf movement, stress avoidance and photosynthesis in Vitis california. Oecologia, 79: $475 \sim 481$

Giannopolitis, C. N.\& S. K. Ries. 1977. Superoxide dismutase. I. Occurrence in higher plants. Plant Physiology, 59: 309 315 .

Guo, L.W. (郭连旺), D. Q. Xu(许大全) \& Y. G. Shen(沈允 钢). 1996. Photoinhibition of photosynthesis without net loss of D1 protein in wheat leaves under field conditions. Acta Botanica Sinica(植物学报), 38: $196 \sim 202$. (in Chinese with English abstract)

Guo, L. W. (郭连旺) \& D. Q. Xu(许大全). 1994. Photoinhibition of photosynthesis in Viburnum odoratissimum leaves under field conditions. Acta Phytophysiologica Sinica (植物生理学 报), 20: $46 \sim 54$. (in Chinese with English abstract)

Krause, G.H. , A. Virgo \& K. Winter. 1995. High susceptibility to photoinhibition of young leaves tropical forest trees. Planta, 197: $583 \sim 591$.

Kursar, T. A.\& P.D. Coley. 1992. Delayed greening in tropical leaves: an antiherbivory defense? Biotropica, 24: $256 \sim 262$.

Kursar, T.A.\& P.D. Coley. 1995. The cost of leaf construction in shade-tolerant rainforest plants. American Naturalist, 141: 421 $\sim 435$.

Lin, Z.F. (林植芳), S.S. Li (李双顺) \& G. Z. Lin (林桂 珠). 1988. The accumulation of hydrogen peroxide in senescing leaves and chloroplasts in relation to lipid peroxidation. Acta Phytophysiologica Sinica (植物生理学报), 14:16 22. (in Chinese with English abstract)

Long, S.P., S. Humphries \& P. G. Falkowski. 1994. Photoinhibition of photosynthesis in nature. Annual Review of Plant Physiology and Plant Molecular Biology, 45: $633 \sim 662$

Lovelock, C.E., M. Jebb \& C. B. Osmond. 1994. Photoinhibition and recovery in tropical plant species: response to disturbance. Oecologia, 97: $297 \sim 307$.

Maxwell, K. \& G.N. Johnson. 2000. Chlorophyll fluorescence - a practical guide. Journal of Experimental Botany, 51: 659 668 .

Meng, Q.W., W. Engelbert, Q. Zou \& S.J. Zhao. 1999. Photoinhibition and photoprotection in Ginkgo biloba leaves: influence of temperature, $\mathrm{CO}_{2}$ and $\mathrm{O}_{2}$. Acta Botanica Sinica(植物学 报), 41: $398 \sim 404$

Meng, Q.W. (孟庆伟), S.J. Zhao(赵世杰), C. C. Xu (许长 城) \& Q. Zou(刍琦). 1996. Phototinhibition of photosynthesis and protective effect of photorespiration in winter wheat leaves under field conditions. Acta Agronomica Sinica (作物学报), 22:
$470 \sim 475$. (in Chinese with English abstract)

Neubauer, E. \& H. Y. Yamamoto. 1992. Mehler-peroxide reaction mediates zeaxanthin formation and zeaxanthin-related fluorescence quenching in intact chloroplasts. Plant Physiology, 99:13 54 .

Osmond, C. B. 1994. What is photoinhibition? Some insights from comparisons of shade and sun plants. In: Baker, N.R.\& J. R. Bowyer eds. Photoinhibition of photosynthesis from molecular mechanisms to the field. Oxford: Bios Scientific Publishers. 1 24.

Osmond, C. B. \& S.C. Grace. 1995. Perspectives on photoinhibition and photorespiration in the field: quintessential inefficiencies of the light and dark reactions of photosynthesis? Journal of Experimental Botany, 46:1351 1362 .

Schreiber, U., H. K. Hormann, K. Asada \& C. Neubauer. 1995. $\mathrm{O}_{2}^{-}$dependent electron flow on intact spinach chloroplasts: properties and possible regulation of the Mehler-ascorbate peroxidase cycle. In: Mathis, P. ed. Photosynthesis: from light to biosphere. Vol. II. Dordrecht: Kluwer Academic Publishers. $813 \sim 818$.

Shen, W. B. (沈文飚), L. L. Xu(徐郎莱)，M. B. Ye(叶茂炳) \& R.X. Zhang(张荣铣). 1996. Study on determination of ASP activity. Plant Physiology Communication (植物生理学通讯), 32:203 205. (in Chinese with English abstract)

Tao, Z.Y. (陶宗娅) \& Q. Zou (刍琦). 2001. Roles of Mehler reaction in dissipating excess light energy in soybean leaves. Acta Phytophysiologica Sinica (植物生理学报), 27:66 72. (in Chinese with English abstract)

Tao, H.Z. (陶汉之). 1991. Studies on the diurnal variations of the photosynthesis of tea plant (Camellia sinensis). Acta Agronomica Sinica（作物学报), 17: $444 \sim 452$. (in Chinese with English abstract)

Tardy, F., A. Creach \& M. Havaux. 1998. Photosynthetic pigment concentration, organization and interconversions in a pale green Syrian landrace of barley (Hordeum vulgare L. Tardmor) adapted to harsh climate conditions. Plant, Cell and Environment, 21: $479 \sim 489$.

Wang, Y.R. (王以柔), H.X. Liu(刘鸿先), P. Li(李平), S. X. Zeng(曾韶西)，L.P. Zhen(甄立平) \& J. Y. Guo(郭俊 彦). 1986. The effect of chilling stress on membrane-lipid peroxidation of photosynthetic apparatus in rice seedlings in the dark and light. Acta Phytophysiologica Sinica (植物生理学报), 12: $244 \sim 251$. (in Chinese with English abstract)

Wiese, C., C. B. Shi \& U. Heber. 1998. Oxygen reduction in the Mehler reactions is sufficient to protect photosystem I and II of leaves against photoinhibition. Physiologia Plantarum, 102: 437 $\sim 446$.

Wu, B. X. (吴邦兴). 1991. Studies on the vertical structure of seasonal rain-forest in Xishuangbanna of Yunnan. Acta Botanica Sinica(植物学报), 33: $232 \sim 239$. (in Chinese with English abstract)

Wu, Z. Y. (吴征镒) \& Y.C. Zhu(朱彦丞). 1987. Yunnan vegetation. Beijing: Science Press. 109 143. (in Chinese)

Xu, D. Q., B. J. Xu \& Y.G. Shen. 1990. Diurnal variation of photosynthetic efficiency in $\mathrm{C}_{3}$ plants. Acta Phytophysiologica Sinica (植物生理学报), 16: $1 \sim 5$.

Xu, D. Q. (许大全), Y.Z. Zhang (张玉忠) \& R.X. Zhang(张 荣铣). 1992. Photoinhibition of photosynthesis in plants. Plant Physiology Communication (植物生理学通讯), 28:237 243 . (in Chinese)

Zou, Q. (刍琦), C.C. Xu(许长城), S.J. Zhao(赵世杰) \& Q. W. Meng (孟庆伟). 1995. The role of SOD in protecting the photosynthetic apparatus of soybean leaves from midday high light stress. Acta Phytophysiologica Sinica (植物生理学报), 21: 397 401. (in Chinese with English abstract) 